\title{
The Brazilian version of the SCOFF questionnaire to screen eating disorders in young adults: cultural adaptation and validation study in a university population
}

\author{
Ananda A. Teixeira, ${ }^{1,2,3}$ Marco A. Roque, ${ }^{2}$ (iD André A. de Freitas, ${ }^{2}$ iD Nicole F. dos Santos, ${ }^{2}$
} Flávia M. Garcia, ${ }^{2}$ iD Júlia M. Khoury, ${ }^{2}$ iD Maicon R. Albuquerque, ${ }^{4}$ (iD Maila de C. das Neves, ${ }^{1,2}$ (iD Frederico D. Garcia ${ }^{1,2,3}$ iD

${ }^{1}$ Departamento de Saúde Mental, Universidade Federal de Minas Gerais (UFMG), Belo Horizonte, MG, Brazil. ${ }^{2}$ Núcleo de Pesquisa em Saúde e Vulnerabilidade, UFMG, Belo Horizonte, MG, Brazil. ${ }^{3}$ Programa de Pós-Graduação em Medicina Molecular, Faculdade de Medicina, UFMG, Belo Horizonte, MG, Brazil. ${ }^{4}$ Departamento de Esportes, Escola de Educação Física, Fisioterapia e Terapia Ocupaciomal, UFMG, Belo Horizonte, MG, Brazil.

\begin{abstract}
Objective: This study translated, culturally adapted, and validated a Brazilian Portuguese version (SCOFF-BR) of the Sick, Control, One Stone, Fat, Food Questionnaire (SCOFF) to screen eating disorders in young adults.

Methods: This study used back-translation to culturally adapt the questionnaire according to International Society of Pharmacoeconomics and Outcome Research principles. The SCOFF-BR validation process involved a sample of men and women aged 18-32 years from a university community. After the participants completed the SCOFF-BR questionnaire, pre-trained researchers interviewed them with the Mini International Neuropsychiatric Interview (MINI). The presence of eating disorders was determined according to DSM- 5 criteria.

Results: Of the 361 subjects, $9.7 \%$ had an eating disorder $(2.2 \%$ anorexia nervosa, $5 \%$ bulimia nervosa, and $2.5 \%$ binge-eating disorder). Using a cutoff point of two positive responses, we obtained a sensitivity of $80 \%$ and a specificity of $71.5 \%$, with an accuracy of $72.3 \%$. The positive and negative predictive values were $23.1 \%$ and $97.1 \%$, respectively.

Conclusion: This study demonstrated that the Brazilian version of the SCOFF questionnaire presents satisfactory accuracy and reliability to screen eating disorders among young adults in the Brazilian university community.
\end{abstract}

Keywords: SCOFF; eating disorders; anorexia nervosa; bulimia nervosa; binge-eating disorder; neuropsychological tests; epidemiology

\section{Introduction}

Increasing and accelerating the diagnostic process of eating disorders (EDs) is crucial for patients. ${ }^{1}$ Early intervention critically depends on early detection of the disorder or its precursors. ${ }^{2-4}$ The positive correlation between symptom severity and treatment refusal highlight the importance of early intervention for individuals with EDs. ${ }^{5}$

Providing reliable tools for screening and diagnosing patients with EDs is essential for clinical practice. ${ }^{6}$ The Sick, Control, One Stone, Fat, Food Questionnaire (SCOFF) is the most widely used screening instrument for EDs and has been culturally adapted to at least 15 different cultures worldwide, maintaining adequate metrological properties, as reviewed in a recently published meta-analysis. ${ }^{7}$

No study has assessed the validity of a Brazilian Portuguese version of the SCOFF (SCOFF-BR) questionnaire

Correspondence: Frederico D. Garcia, Universidade Federal de Minas Gerais (UFMG), Departamento de Saúde Mental, Av. Alfredo Balena, 190, sala 240, CEP 30130-100, Belo Horizonte, MG, Brazil. E-mail: fredgarcia@ ufmg.br

Submitted Sep 04 2020, accepted Dec 10 2020, Epub Mar 012021. for the screening of EDs in a university population. This study translated, culturally adapted, and validated a Brazilian version of the SCOFF questionnaire in a population of young adults. We hypothesized that this culturally adapted Brazilian version of the SCOFF questionnaire would be a reliable tool to screen EDs in Brazilian young adults.

\section{Methods}

\section{Study design}

This cross-sectional observational study assessed the validity and reliability of the SCOFF-BR questionnaire with a convenience sample of adults from a university community.

How to cite this article: Teixeira AA, Roque MA, de Freitas AA, dos Santos NF, Garcia FM, Khoury JM, et al. The Brazilian version of the SCOFF questionnaire to screen eating disorders in young adults: cultural adaptation and validation study in a university population. Braz J Psychiatry. 2021;43:613-616. http://dx.doi.org/10.1590/15164446-2020-1667 


\section{Participants}

Undergraduate and graduate students of both sexes, aged 18 to 32 years old, were recruited from the campuses of the Universidade Federal de Minas Gerais. Individuals with conditions that could influence food intake or body weight, such as hyperthyroidism, severe gastrointestinal disease, or those taking anorexigenic medications for medical reasons were excluded. Approximately 60,000 people circulate the university's campuses daily. Data collection occurred from September 2018 to April 2019.

\section{Test methods}

\section{From the SCOFF to the SCOFF-BR}

This study adhered to the guidelines of the International Society of Pharmacoeconomics and Outcome Research Taskforce for Translation and Cultural Adaptation ${ }^{8}$ to develop the Brazilian version of the SCOFF (SCOFF-BR). We obtained permission from the authors of the SCOFF to culturally adapt a Brazilian Portuguese version of the instrument. Four bilingual ED specialists from different regions of the country translated the English version of the SCOFF questionnaire into Brazilian Portuguese and edited it for syntax. Since there are slight regional variations in Brazilian Portuguese, we considered it critical to provide an instrument that would be useful in each region. The ED specialists reconciled the four versions in a virtual meeting, producing an intermediary version of the SCOFF-BR. A native-English-speaking linguist backtranslated this intermediate version of the SCOFF-BR. The study team and a consultant linguist reconciled it into a single forward translation, comparing and adjusting the final version of the SCOFF-BR. The authors harmonized all the translations and the source version, performing additional editing and improving the comprehension of the questions. Finally, the research team proofread the final version of the SCOFF-BR and used it for this study.

Mini International Neuropsychiatric Interview (MINI)

The present study used the updated, validated full Brazilian version of the MINI. ${ }^{9}$ The interviewers were medical students and psychiatry residents with previous training in semiology and psychiatric nosology. All interviewers underwent a brief training session on the MINl's administration and interpretation.

\section{Procedures}

The interviews were performed in an office to improve disclosure. After a brief explanation of the research methods, the interviewers trained each participant to fill out the questionnaires on a tablet computer. After the SCOFF-BR was completed, a researcher blinded to the results interviewed each participant for demographic data (i.e., biological gender, race, date of birth, marital status, and family income), a brief medical history, and current medications. After the questionnaires were completed, a structural interview with the MINI structured was performed, and the participant's height (meters) and weight (kilograms) were measured with a calibrated W200A digital scale and stadiometer (Welmy, Santa Bárbara d'Oeste, Brazil). To calculate the body mass index (BMI), the interviewers used the Quetelet index.

We contacted a randomly selected subsample of $30 \%$ of the participants to perform a retest one month after the initial interview.

\section{Analysis}

For the validity assessment, we calculated the sensitivity, specificity, and positive and negative predictive values for each test's threshold with a 95\% confidence interval (95\% $\mathrm{Cl}$ ). The Kuder-Richardson 20 (KR20) coefficient determined the consistency (reliability). To determine the best cutoff point, we calculated a receiver operating characteristic (ROC) curve and the area under the curve. ${ }^{10}$ SPSS version 11 for Windows ${ }^{\circledR}$ (IBM, New York, USA) was used for the statistical computations.

\section{Ethics statement}

The local research ethics committee approved the study, and all participants gave written informed consent before taking part in any study procedure.

\section{Results}

\section{The Brazilian version of the SCOFF questionnaire (SCOFF-BR)}

Table 1 shows the original English and Brazilian versions of the SCOFF.

\section{Participants}

\section{Participant flow}

Of the 568 subjects invited to participate in the study, 207 $(36.5 \%)$ declined. The main reason for refusal was lack of time to perform the interview (Figure S1, available as online-only supplementary material).

\section{Baseline demographic and clinical characteristics}

The study assessed 361 subjects, 192 (53.2\%) women and $169(46.8 \%)$ men whose mean ( \pm standard deviation [SD]) age of $22.24 \pm 2.6$ years (range 18-32). According to participant self-report, $229(63.4 \%)$ were white, 122 $(33.8 \%)$ were non-white, and 10 (2.8) did not respond.

Their mean BMI was $23.37 \pm 3.78 \mathrm{~kg} / \mathrm{m}^{2}$. Twenty-three $(6.4 \%)$ participants were underweight $(\mathrm{BMI} \leqslant 18.5), 73$ $(20.2 \%)$ were overweight $(\mathrm{BMI}=25$ to 30$), 28(5.3 \%)$ were obese and $273(68.1 \%)$ were normal weight. Nine (2.5\%) participants reported previous treatment with a gastric balloon or bariatric surgery for obesity, and $52(14.4 \%)$ had undergone at least one aesthetic surgery in the past.

\section{Eating disorders diagnosis}

According to the MINI data and DSM-5 criteria, 35 (9.7\%) of the participants presented an ED, $32(91.4 \%)$ females, 
Table 1 Sick, Control, One Stone, Fat, Food Questionnaire (SCOFF): comparison of the original English and Brazilian versions (SCOFF-BR)

\begin{tabular}{|c|c|}
\hline SCOFF & SCOFF-BR \\
\hline $\begin{array}{l}\text { 1. Do you make yourself "sick" because you feel } \\
\text { uncomfortably full? }\end{array}$ & $\begin{array}{l}\text { 1. Você provoca vômito quando está se sentindo desconfortavelmente } \\
\text { cheio? }\end{array}$ \\
\hline $\begin{array}{l}\text { 2. Do you worry you have lost "control" over how much you } \\
\text { eat? }\end{array}$ & 2. Você se preocupa de ter perdido o controle do quanto você come? \\
\hline 3. Have you recently lost "one" stone in a 3-month period? & 3. Você perdeu recentemente mais de 5 quilos num periodo de 3 meses? \\
\hline $\begin{array}{l}\text { 4. Do you believe yourself to be "fat" when others say you } \\
\text { are too thin? }\end{array}$ & $\begin{array}{l}\text { 4. Você acredita estar gordo(a), apesar das outras pessoas dizerem que } \\
\text { você está muito magro(a)? }\end{array}$ \\
\hline 5. Would you say that "food" dominates your life? & 5. Você diria que a comida domina a sua vida? \\
\hline
\end{tabular}

and $3(8.6 \%)$ males. There were $8(2.2 \%)$ cases of anorexia nervosa, $18(5 \%)$ of bulimia nervosa and $9(2.5 \%)$ cases of binge-eating disorder. There was one male in each ED group.

\section{SCOFF-BR results}

According to the ROC curve (Figure 1), the optimal threshold for the questionnaire was two or more positive answers. At this cutoff point, the sensitivity and specificity levels were 80 and $71.5 \%$, respectively. The area under the curve was $82 \%$ and the accuracy was $72.3 \%$. The positive likelihood ratio was $2.81(95 \% \mathrm{Cl} 1.93-3.81)$ and the negative likelihood ratio was $0.28(95 \% \mathrm{Cl} 0.12-$ 0.53). Table $S 1$, available as online-only supplementary material, shows the sensitivity and specificity for anorexia nervosa, bulimia nervosa, or binge-eating disorder independently.

With a threshold of two positive answers, 121(33.5\%) SCOFF-BR questionnaires were positive, corresponding to 28 ED cases and 93 false positives. The SCOFF-BR questionnaire missed seven positive cases of EDs (false negatives) (Table $\mathrm{S} 2$, available as online-only supplementary material).

\section{Internal consistency reliability}

Using the correlation matrix, the KR20 coefficient value was $0.47(95 \% \mathrm{Cl} 0.38-0.55)$ for each of the five items of the SCOFF-BR.

\section{Temporal stability}

A retest of 123 (34.1\%) participants yielded an intraclass correlation coefficient of $0.73(F=3.73, p \leqslant 0.001)$, which indicates an acceptable test-retest correlation.

\section{Discussion}

The purpose of this study was to translate and culturally adapt the original English version of the SCOFF questionnaire to Brazilian Portuguese and assess the validity and reliability of this Brazilian version (SCOFF-BR) to screen EDs in an adult university population. Our results demonstrate the reliability of the SCOFF-BR for screening EDs in this population. Unlike most previous studies, ${ }^{7}$ this study used DSM-5 (which includes binge eating disorder), rather than DSM-IV criteria, to diagnose EDs. Moreover,

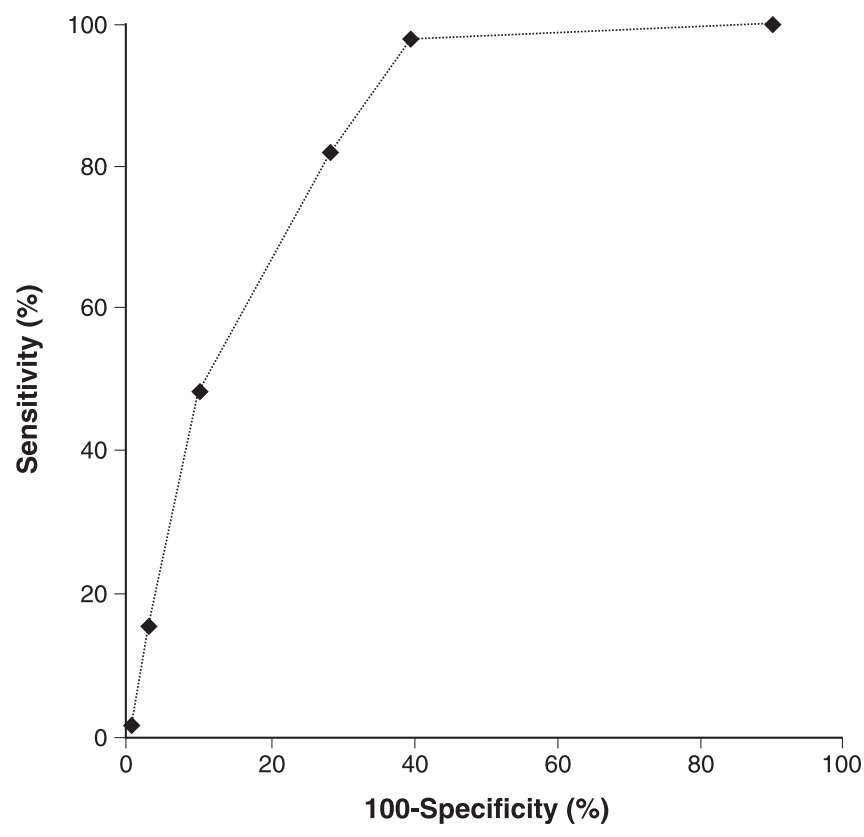

Figure 1 Receiver operating characteristic (ROC) of the Brazilian version of the Sick, Control, One Stone, Fat, Food Questionnaire (SCOFF).

the sample size was sufficient to represent the assessed population and, unlike previous studies, it included both men and women and subjects from all academic areas, thus widening the representation of subgroups and minimizing the impact of restricting the sample to nutrition or medicine students.

SCOFF-BR users must be aware that, as a screening instrument, it may over-identify EDs. When clinicians find a subject with a positive SCOFF-BR score, they should extend their anamnesis regarding eating behaviors, dysmorphophobia, and other psychiatric symptoms before diagnosing an ED or referring the patient to a specialist.

Some methodological points may limit the strength of this study. Other specified feeding or EDs or unspecified feeding or EDs were not assessed, although they are prevalent. $^{11}$ Second, the sample did not include older adults, adolescents, or children, which restricts the instrument to an adult sample. Finally, despite our efforts to form a generalizable sample and the low refusal rate, this study involved a convenience sample. 
Moser et al. ${ }^{12}$ recently published a final report on an unvalidated culturally adapted Brazilian version of the SCOFF questionnaire. Although they also followed ISPOR ${ }^{8}$ guidelines, their version diverged slightly from that of the present study, principally regarding the definition of "one stone." While Moser et al. ${ }^{12}$ considered a stone equivalent to $6 \mathrm{~kg}$, we preferred $5 \mathrm{~kg}$ due to anthropometric differences between the European and South American populations. Brazilians have lower mean height and weight than Europeans and North Americans. Hence, a lower weight yields a more sensitive result.

In conclusion, the present data confirm that the SCOFFBR can accurately and reliably screen subjects at risk for EDs in a Brazilian Portuguese speaking university population.

\section{Acknowledgements}

This study was partially supported by Fundação de Amparo à Pesquisa do Estado de Minas Gerais (FAPEMIG; grants APQ-02572-16, APQ-04347-17) and Conselho Nacional de Desenvolvimento Tecnológico (CNPq; grant 313944/2018-0).

The authors are grateful to professors Rosane Pilot Pessa, Silvia Freitas, Rodrigo Grassi, and Beatriz Rocha for translating the original version of the SCOFF questionnaire

\section{Disclosure}

The authors report no conflicts of interest.

\section{References}

1 Garcia FD, Grigioni S, Allais E, Houy-Durand E, Thibaut F, Déchelotte P. Detection of eating disorders in patients: validity and reliabi- lity of the French version of the SCOFF questionnaire. Clin Nutr. 2011;30:178-81.

2 Treasure J, Russell G. The case for early intervention in anorexia nervosa: theoretical exploration of maintaining factors. Br J Psychiatry. 2011;199:5-7.

3 Currin L, Schmidt U, Treasure J, Jick H. Time trends in eating disorder incidence. Br J Psychiatry. 2005;186:132-5.

4 Nazar BP, Gregor LK, Albano G, Marchica A, Lo Coco G, Cardi V, et al. Early response to treatment in eating disorders: a systematic review and a diagnostic test accuracy meta-analysis. Eur Eat Disord Rev. 2017;25:67-79.

5 Griffiths S, Rossell SL, Mitchison D, Murray SB, Mond JM. Pathways into treatment for eating disorders: a quantitative examination of treatment barriers and treatment attitudes. Eat Disord. 2018;26:556-74.

6 Garcia FD, Grigioni S, Chelali S, Meyrignac G, Thibaut F, Dechelotte $P$. Validation of the French version of SCOFF questionnaire for screening of eating disorders among adults. World J Biol Psychiatry. 2010;11:888-93.

7 Kutz AM, Marsh AG, Gunderson CG, Maguen S, Masheb RM. Eating disorder screening: a systematic review and meta-analysis of diagnostic test characteristics of the SCOFF. J Gen Intern Med. 2020;35:885-93.

8 Wild D, Grove A, Martin M, Eremenco S, McElroy S, Verjee-Lorenz A, et al. Principles of good practice for the translation and cultural adaptation process for patient-reported outcomes (PRO) measures: report of the ISPOR task force for translation and cultural adaptation. Value Health. 2005;8:94-104.

9 Amorim P. Mini International Neuropsychiatric Interview (MINI): validação da entrevista breve para diagnóstico de transtornos mentais. Rev Bras Psiquiatr. 2000;22:106-15.

10 Zweig MH, Campbell G. Receiver-operating characteristic (ROC) plots: a fundamental evaluation tool in clinical medicine. Clin Chem. 1993;39:561-77.

11 Mustelin L, Lehtokari VL, Keski-Rahkonen A. Other specified and unspecified feeding or eating disorders among women in the community. Int J Eat Disord. 2016;49:1010-17.

12 Moser CM, Terra L, Behenck AD, Brunstein MG, Hauck S. Crosscultural adaptation and translation into Brazilian Portuguese of the instruments Sick Control One Stone Fat Food Questionnaire (SCOFF), Eating Disorder Examination Questionnaire (EDE-Q) and Clinical Impairment Assessment Questionnaire (CIA). Trends Psychiatry Psychother. 2020;42:267-71. 